\title{
Factors That Influence New Principal's Transition Actions and Decisions in Colleges of Education, Ghana
}

\author{
Caroline Aggrey-Fynn
}

Accra Institute of Technology

\begin{abstract}
This study was to investigate the factors that influence new college of education principals during transition. The study adopted phenomenology as the research design and data was collected from ten respondents from public colleges in Ghana. The findings showed that actions and decisions of the principals during their transitions were influenced by four categories of factors which were: internal factors, internal individuals, external factors and external individuals. However, the actions and decisions were influenced more by internal and external factors and people rather than the principals' personal beliefs and philosophies. In practice, the findings of the study opens up the decision influencing factors in transition and serves as a guide for college leaders and other school leaders in transition. The study recommended that new principals should pay attention to internal and external factors and individuals as they set transition goals, priorities and actions to help align interests and reduce resistance to any change situation that may result from the transition.
\end{abstract}

Key words: Factors, influence, principal, transition, decisions.

\section{Introduction}

Hesselbein (2012) viewed leadership transition as an integral process for all leaders of an organization which presents a remarkable opportunity to move forward with a new understanding of complexities, challenges and changes the organization must address. In transitioning into a position as a principal, should there be guiding factors that should influence the new principal's transition actions and decisions? Obviously, nothing takes place without a precipitating factor. This study investigates the factors that influence a new College of Education principal's decisions and actions in their transition management.

\section{Problem Statement}

In transitioning into a position as a principal, there are processes that the person should have gone through. In a grounded theory study on the principals' transition experience, Cockley (2011) found that in transitioning into their new principal role, actions and decisions made are most often the result of other factors rather than the principal's own beliefs about what should be done. Basically, the decision influencing factors are more of external factors than internal - 'leadership style'. These factors shape the transition by influencing priorities and in determining what to do (Cockley, 2011). Studies by Afful-Broni (2006), Bagi (2015), Cockley (2011), Dethloff (2005), Ejimabo (2015), Gallos (2008), and Meleis et al. (2000) also identified factors that influence transition actions and decisions of principals who are new to their roles. However, owing to socio-cultural differences, one may not be able to ascertain their universality and relate them to the Ghanaian context. This called for investigation to ascertain factors that influence transition actions and decisions of college of education principals in Ghana.

\section{Research Objective}

To investigate the factors that influence transition decisions and actions 


\section{Literature Review}

New principals have perhaps, a lot to adapt to and learn on their job so that the necessary impact can be attained based on their visions, yet support is limited. According to Yeatts (2005), transition actions are not simply automatic. They are influenced by certain identified characteristics or properties. Meleis at al. (2000) identified some transition properties which may influence decisions and actions. They include awareness, engagement, change and difference, time span, critical points and events.

In a grounded theory study conducted, Cockley (2011) identified a number of transition decision influencing factors. They include finances and "financial limitations, district philosophy, district typology, prior principal's legacy, school culture, school designation, superintendent and central office administration, leadership style" and personal beliefs and values (pp. 156-171). Cockley, (2011) found that in the new role, the principal's actions and decisions were often the result of factors other than the principal's own beliefs about what should be done. These factors shape their transition by influencing them in setting priorities and in determining what to do. Basically, the decision influencing factors are more of external factors than internal factors (Cockley, 2011; Meleis et al., 2000).

Also, in a qualitative ethnographic study, Ejimabo (2015) explored the impact of decision making in organizational management and leadership activities that influence organizational creativity, effectiveness, growth, success, and goal achievements. Ejimabo identified what he termed as "elements and unavoidable factors" which influence leadership decisions in many organizations in the society. They include education and experience, belief and cultural environment, cognitive biases, leadership influence, politics and policy, technology, age and individual difference, time and change, leadership style and communication practices (p.4). Matthews and Crow (2003) noted that professional, organizational and personal socialization influence role conceptions and decisions.

Change is nothing new to leaders, or their constituents as organizations cannot achieve success if they do not realign to contemporary practices. Conditions change and assumptions and practices of past years are no longer applicable. Certainly, there must be innovation and that means change (Ejimabo, 2015; Bridges \& Mitchell, 2000). Mary Poplin, in her article regarding this transformation stated, "Instructional leadership having outlived its usefulness, our profession now calls on administrators to be the servants of collective vision, editors, cheerleaders, problem solvers and resource finders" furthermore, "we must not only be selfconscious about change, but we must also encourage it in others" (cited in Cunningham, 2000, p. 8). Thus, transition involves change and as it occurs, perceptions and plans to make a significant difference take place causing the change effect in the process and all stakeholders must be part of it.

Afful-Broni (2006) asserted that financial matters are central to the services rendered by administrators in any organization, and every decision made by the school head has financial connotations. In this regard, he suggested that the head must be very circumspect in this sensitive area because any problem in this domain can break the leader and jeopardize the future of the institution. Though I acknowledge that finances and financial limitations impact decisions, I would rather agree with the earlier statement that not all decisions have financial commitments.

Essentially, any senior leader who assumes a new role picks up from where the predecessor left off (Bagi, 2015) in terms of relationship established and leadership style (Cockley, 2011; Earley et al., 2013; Weindling \& Dimmock, 2006). The new principal may be influenced by a legacy of high standard (Shoho \& Barnett, 2010) or low standard (Sieber, 2002) set by the predecessor. As stated, "The ghosts of the past still rule the school. The new leader must acknowledge and respect the ghosts of his/her predecessors" (Rooney, 2000; p.77). Apparently, the legacy of the previous principal's leadership style, whether negatives or positives, help shape actions and decisions during the transition period.

The existing school culture is a priority for immediate actions and decisions. With the importance of culture stressed (Ejimabo, 2015; Cockley, 2011; Schein, 2010; Gallos, 2008), obviously, culture has a significant role to play in transition decisions and actions but one must be mindful of the school culture in the context of national mandates. Regardless of the initial state designation, it is a factor that influenced decisions and actions during transitions (Cockley, 2011). In an era of testing and accountability, there is continued 
pressure to improve students' performance. In a school with a designation of academic emergency or academic watch, the designation plays a large part in their decisions such as focusing on meeting staffing and other basic needs, through social service agencies, testing data and character education to promote learning.

The superintendents' directives or lack of it shape decisions (Ejimabo, 2015; Cockley, 2011). Expectations and clear instructions from the superintendent on what they should do or change in the school, ranging from general test scores, support and guidance provided by central office administration are needed by the new principal. Autonomy and data requirements also influence actions and decisions. Although there are numerous examples of external factors that influence transition actions and decisions, Ejimabo (2015) and Cockley (2011) found that internally, one's own leadership style, personality and personal values are included. That determines decisions, tools and the resources to execute the job and make or unmake a positive impact. Gallos (2008) theorized that failure during the time of transition could not only ruin success, but also ruin the career of a new leader. A new principal should assess what kind of leadership will be required for the situation in which he or she is inheriting. Afful-Broni (2006) stated that, "a high degree of democratic leadership is recommended in a university setting" whereas in a well-established old university, a blend of laissez faire, democracy and autocracy occasionally may be the best (p.142). This means that even though some leaders may apply a type of leadership style, it is ideal to have a combination of them or better still, base the choice on the situation. In other words, no one leadership style can be judged as the perfect option. Certainly, leadership style employed by the new principal is an important consideration for transformation and cannot be over-emphasized in a new principal's transition decisions and actions.

According to Matthews and Crow (2003), there are three sources of socialization for school leaders: professional, organizational and personal. These influence role conceptions. They suggest that professional socialization and the role of the administrator are influenced by outside expectations. Expectations of the larger society in general and university training in particular communicate regarding how to enact the role. These influences emphasize the patterns of beliefs, values and assumptions around a role (Ejimabo, 2015; Matthews \& Crow, 2003). Matthews and Crow (2003) noted that "Becoming an innovative school leader is also influenced by sources that occur when you enter your first school as an assistant principal or principal. At this stage, the more generic skills and administrative perspective learned during university training are reinforced, modified, and expanded as principals and assistant principals learn how things are done here" (Matthews \& Crow, 2003; p. 265) in terms of politics and policy, technology, age, individual difference and communication practices. Within the school, the students, teachers, and parents influence the socialization of the new principal and vice-principal. These key players help to shape the way the new administrator sees him or herself (Ejimabo, 2015; Matthews \& Crow, 2003). Finally, the personal socialization stage is how friends and families influence the new principals and vice-principals. "Family members and friends can be critical sources of support for encouraging role conceptions that involve more innovative images" (Matthews \& Crow, 2003, p. 266).

\section{Research Methodology \\ Research Design}

The study used phenomenology as the design to investigate the problem because it is flexible and gives more freedom in the interview process to explore essences of people's experiences (Miles, Huberman, \& Saldana, 2014). Also, it provides insights into the phenomenon (Creswell, 2014). Therefore, it made it suitable to answer the research questions on the factors that influenced the College of Education principal's transition decisions and actions to achieve the set objective.

\section{Sample and Sampling Procedure}

A sample of ten respondents was used for the study and purposive sampling was used in the sampling. "The purpose of a purposeful sample is to focus case selection strategically in alignment with the inquiry's purpose, primary questions and data being collected" (Patton 2015, p.264). Based on the selection criteria, it was identified that 23 out of the 46 principals had just assumed the role as substantive principals with less than one (1) year experience while five (5) of them were in acting principal capacities. Only eighteen (18) 
principals were within the range and qualified for the study. However, considering efficiency, reliability and availability, only 10 principals could avail themselves and thus formed the sample for this study.

\section{Research Instrument}

Interview protocol was used to elicit information from the principal's transition management in line with the objective and research question to provide valuable and comprehensive information about the study. Following Creswell's (2007) framework, the interview protocol included instructions for the interviewer (opening statements, transition statements and probes for further exploration of participants' responses), guiding research questions and recording space for the interview data.

\section{Data Collection Procedure}

The respondents were met face-to-face and by telephone conversations. An electronic mail (e-mail) was sent to the 10 sampled respondents. The e-mail spelt out the purpose of the study and the thematic areas of the data collection protocol (interview). The interview protocol areas of concern included instructions for the interviewee; demographic and background questions; and factors that influenced transition actions and decisions of new college principals.

During the interview meeting, the consent process guidelines were explained to the respondents. Copies of the signed forms were given to respondents to serve as a commitment to participate in the study. The interview progressed systematically as designed. After each question, I paused for the response. Where further clarification was needed, it was provided. I probed for more information where necessary until all the probing questions were exhausted. The process was recorded with a digital recorder for accuracy in recall of information. Notes were also taken throughout the interviews as a back-up source of data. Creswell's (2009) ethical considerations were used to avoid biases.

\section{Data Analysis}

Data transcription, organization into themes and coding were done manually using thematic content analysis method. All the field notes were transcribed to give a full picture of what transpired and minimize the likelihood of being biased in the analysis. The data was then organized into sections (themes) after transcribing to make it easy to retrieve. Computer software, Excel for Windows was then used to compute the frequency of significant statements made by respondents. The analysed data was presented in a descriptive form and sample significant statements quoted. Member-checking was employed to ensure accuracy, validity and reliability.

\section{Results}

These are the details on the factors that influenced the transition actions and decisions of the respondents. Categorically, those decision influencing factors were basically: internal factors, internal individuals, external factors and external individuals.

\section{Internal Factors that Influenced Transition Decisions}

All the principals discussed how internal factors shaped the actions and decisions they took. These internal factors and their corresponding responses in brackets comprised college history / status quo/vision (4), the leadership style (6), quality assurance (6), motivational needs / boosting morale (3), gender responsiveness (2), and financial challenges (5). Four (4) respondents reported that the history/"status quo"/vision of their individual colleges mattered to them in an attempt to preserve and continue the good cultural practices that existed. The vision of their respective colleges made them emphasis discipline and academic excellence. Significant quotes are:

\footnotetext{
"Because of the history and vision, the community takes interest in the college's image ... so we were all guided by the rich history of the college not to go against the norm. ... Discipline and academic excellence were enforced. We also set realistic targets." (Krop)
} 
"There was the interest in the students to learn hard and aspire. So, it was just a matter of I came to meet the tradition - the "status quo" ... I said, "eh! It is not just a matter of saying you will pass but you have to pass with good grades." (Ace)

"History and vision to make the college an icon of excellence caused us to emphasize discipline and academic excellence". (Kum,)

"I would say the vision of the college is one and past records. The standard was there. I made sure everybody worked and I worked very hard." (Buri)

Per six (6) respondents, leadership style was not left out. It also shaped the principals' actions and decisions. All respondents employed all inclusive leadership. Occasionally, they sounded autocratic when urgent, bold and realistic decisions had to be taken. Quotes are:

"I used the open-door administration, mainly the democratic style. However, sometimes the autocratic style was applied when I felt there was the need for urgent bold decisions to be taken". (Ace)

"I never wanted to lord over anybody. Because we were united, we made productive and binding decisions." (Sle)

"Specific, realistic and achievable targets were set owing to the leadership trainings I had". (Roke)

"Whatever I did, I involved everybody. Because of that, we were all involved in decisions about the college." (Krop)

“My administration was open." (Pon)

"Tell you what? Madam, in leadership, I don't believe in applying one particular style. Whatever situation that arose called for an approach and decisions to take." (Buri)

Six (6) respondents were very particular about quality assurance issues as the entire college improvement standard depended on that. This made some of them set good standards and intensify supervision. Here are quotes:

"We are very particular about quality assurance issues here. For example, we increased 'prep' (study) hours from two (2) to three (3) and encouraged group discussions. We also did staff appraisal." (Bec)

"Internally, quality assurance issues also shaped my actions towards enhancing academic work." (Roke)

"Though I would say that 'I am a simple person, I won't say that I want things done in a simple way. ... I value quality and it reflects in all I do". (Ace)

"Yes, quality assurance issues were very important as the entire college improvement standard depended on that. This actually encouraged the setting of achievable standards and the intensive supervision." (Kum)

“Action plans were duly followed...” (Soko)

"The strong desire to positively influence quality pushed me to emphasize and enforce discipline ..." (Mom)

The respondents' being cautious of the importance of motivation in work output, four (4) respondents were moved by that to set up the principal's excellence awards for best-performing students and hard-working staff to encourage them to work harder. Here are significant quotes: 
"To motivate both staff and students to work hard, I instituted the principal's excellence awards for best-performing students and staff and on gender basis." (Krop)

"You know I just mentioned that I gave out prizes. I did that to boost staff and students morale to work hard." (Krop)

"When I assumed this new office, some administrative staff were not recognized. There was the need to effect positive change. This led to the creation of office space for them. Honestly, they were happy." (Roke)

"The activities of the chairperson rather motivated me. They urged me on in every decision I took." (Kum)

Some of the respondents (2) considered gender owing to the awareness creation and the need to be gender responsive. Thus, the focus was gender balance and empowerment. Quotes are:

"The internal need for gender equality. Because of this, I set the pace and I achieved gender parity in admissions for the following year". (Mom)

"Gender discrimination gave me a strong desire to empower these girls. So, in fact, when I tell them to study for the sake of gender equality, they understand." (Buri)

Seriously challenged by financial issues in terms of taxes, supplies and examination fees, five (5) of the respondents stated that in most cases, students fees were mainly used to bail the college. Additionally, monies were also borrowed from other sources such as staff funds to support. Significant quotes are:

"Because of financial challenges, we discussed with the SRC and they paid extra fees to support." (Bec)

"To avoid being dragged to court on tax issues and supplies, I appealed to the staff for loan. Within five to six months - by October ending, we didn't owe anybody". (Sle)

"We decided to use part of staff's teaching practice supervision allowance and SRC dues to support this tiling project." (Soko)

"I personally appealed to the students to support the painting of the buildings and they did." (Krop)

"Because of inadequate funding, we charged the students. For the sake of partnership in development, they agreed to help their own college." (Roke)

\section{Internal Individuals that Influenced Transition Decisions}

The new principal's transition actions and decisions were also influenced by some internal individuals. These individuals and their corresponding responses in brackets comprised the principals themselves (5), college council (2), prior principal (5), vice-principals (2), staff members (2), and students (10). Mentioning how the respondents as individuals influenced their decisions, five (5) of them stated that, their own personal philosophies to make an impact pushed them to transform their respective colleges. Significant quotes:

"My personal philosophy is to make an impact wherever I happen to be pushed to make, for example, the decision of putting up a guest house and create the Agric Village and the many other developmental projects, as well as the institution of the Principal's Academic Excellence Award to motivate students to learn". (Roke)

"I am interested in modernizing every environment that I am in. And for me fear doesn't exist. These are the driving forces - 'what is new? What can we do better?' So, I pick here and there to match up to levels". (Pon) 
"For me anything that is worth doing, is worth doing well and that things done by halves are never done right ... if I am to do it, then I will do it to the best of my ability." (Sle)

"Well, I will say that "knowing that you are in charge of everything at a point in time, you will have to make a difference." (Ace)

"The formation we are given makes me sympathize with people. That made me passionate about people's suffering so much that I made the college pay and register some students for exams even before they paid their fees (laughs)." (Bec)

According to two (2) respondents, their respective college councils gave them the moral support and guidance to implement college development plans. The roles of the council chairpersons were instrumental. Quotes are as follows:

"The activities of the new chairperson of the council motivated me a lot. He pledged the support of the council in the implementation of plans I had for the development of the college." (Kum)

"Internally, the council chair of the college guided and gave me the moral support." (Mom)

Five (5) respondents reported that prior principals also influenced their decisions. The respondents explained that the mistakes of prior principals, negative comments from some colleagues, the marginalization of some staff and factions created by some former principals "predecessor errors" served as a check on their administration. Quotes are:

"The past principal made some mistakes. I heard the comments which shaped my plans because I knew it was a check on my administration." (Ace)

"I was also guided by mistakes of the principal I succeeded in order not to step on other toes." (Kum)

"What had happened and what brought me to this position. ... The mistakes of my predecessor ... The experience helped. I brought everybody on board.” (Bec)

"The outgoing principal urged me to be fair and firm." (Krop)

"The former principal requested that I empowered the female students. That boosted my personal drive to do that." (Buri)

The vice-principals were also mentioned by two (2) respondents as influencing their decisions. These vice-principals requested the support of the new principal to help manage some critical administrative issues that prevailed in the respective colleges. Here are quotes:

"My vice-principal mentioned some few critical issues to me.

I'll not mention them. They really guided my decisions." (Soko)

"But for the vice-principal, I wouldn't have taken up the

appointment. ... There were huge administrative issues". (Roke)

Some staff members (2) also availed themselves by providing hints and pieces of advice in the areas of suggestions as to how to manage and solve issues. Significant quotes are:

"Some staff members also availed themselves by providing hints and pieces of advice in the areas of suggestions as to how to manage and solve issues." (Mom)

"Staff members offered some information for favuor but I cautioned against misinformation”. (Roke)

All the respondents (10) noted that students' achievements as key objective of the existence of the college which influenced their decision. Students actually dominated the internal individuals who influenced decisions in the college. Here are significant quotes: 
'Students' achievement and success were important to us. It is the main reason the college exists. So, the entire struggle to procure logistics and get staff to work were all motivated by the urge for students' achievement." (Buri)

"The zeal for academic excellence informed my decisions." (Soko)

"There had never been a $1^{\text {st }}$ Class student in the college. That pushed me to adopt measures to enhance learning." (Roke)

"Students' need influenced my decision to lobby for the SRC to buy a generator for their learning." (Kum)

"Tutors were persuaded to upgrade themselves to give students quality tuition." (Mom)

"The aim was to train the best teachers in Ghana. This key objective motivated us to map out an operational monitoring plan." (Bec)

“The students' success was my priority ...” (Sle)

"From previous council meetings, I noticed that former principals had to answer for students' non-performance. That meant we had to meet standards and expectations." (Krop)

"I was accountable to the society for students' achievements hence my decision to provide everything necessary for teaching and learning." (Pon)

"We wanted to produce $1^{\text {st }}$ Class teachers ... so the decision for qualified staff." (Ace)

\section{External Factors that Influenced Transition Decisions}

External factors that emerged as influential in all the principals' transition decisions and actions included the upgrading of colleges (10) into tertiary institutions and expectation and needs of the community (2) with their corresponding responses in brackets.

The upgrading of colleges into tertiary institutions as the dominant external factor called for checks and assessment by the National Accreditation Board (NAB) and the National Council for Tertiary Education (NCTE) owing to set standards and policies designed for the colleges. They needed to put systems and structures in place and also tackle development to avoid falling out of place. The following are significant quotes:

"We were moving from, I would say secondary stage to tertiary. ... To put ourselves in that perspective of tertiary institutions, there was the need for proactive decisions to merit that status." (Mom)

"The National Accreditation Board didn't want to give us accreditation because of our computer laboratory. This forced us to seek support to refurbish it." (Sle)

"The tertiary status of colleges is a part of it ... my objective was, we should do things as tertiary institutions do, so that also served as a good guide." (Kum)

"To some extent, the philosophy of education and upgrading of the colleges influenced my decisions. For instance, the need for tutors with required qualifications made me encourage them to pursue Master's degree in relevant subject areas (laughs)." (Bec)

"During the period, the National Accreditation Board came for assessment of the colleges so definitely, it was a strong external factor with standards to go by." (Ace) 
"I had the urge to persuade tutors to go and upgrade themselves as the standard of the colleges had changed. Now tertiary." (Soko)

"Staff had to improve academically and professionally since the colleges havd become tertiary." (Buri)

"For example, because of the new status, we had to paint the buildings, they were dirty." (Krop)

"Because of the tertiary ... staff status had to match. Most of them had to go back to school." (Pon)

"After benchmark visits to other colleges, I said hey! This college needs a face lift. We changed the outmoded furniture." (Roke)

Two (2) respondents reported that the needs and expectations of the community also informed their decisions. Significant quotes:

"Then community expectations ... for example, where possible and appropriate, we allowed the community to use our facilities, participate in our programs .... and also gave them admission quota. Also, because of the church, we strictly enforced discipline”. (Bec)

"We wanted to live in harmony with the community and vice versa. Hence, our decision to establish rapport, invite them to our programs and give them admission quota." (Pon)

\section{External Individuals that Influenced Transition Decisions}

All 10 respondents mentioned that their decisions and actions were also influenced by some external individuals who comprised people outside their immediate environment. Such individuals included role models and relevant publics (old students, friends and the traditional leaders within the colleges' external community). Majority of the respondents (8) mentioned that their decisions and actions were also influenced by role models. Quotes on role models are:

"Women in position and with high reputation. Such women were my role models. That also contributed to my decision to empower the girls." (Buri)

"I admired the head of a senior high school to the extent that her sense of security encouraged me to plan with my development team to wall our college." (Kum)

"Externally, those members, in other words principals, who had been in positions for long, were seen as role models. Their behaviours, attitudes and advice were worth emulating." (Mom)

"I see simple women and I admire them. I saw Florence Dolphine ... and Susana Kennedy .... as simple women with position. They were very humble. I said, 'Eeei,' ... I admired her so much. These people made me humble in my dealings with people." (Ace)

"When I got the appointment, actually, I was not certain. At a point, I was torn between 'take it' or 'leave it'. I called and discussed it with the Vice-Chancellor. He is my role model. He said I should give it a try because I would make it. That motivated me to take it." (Roke)

"For external individuals who influenced my decisions in the period, I would mention Prof. ... my mentor actually worked on me to make sure that I did my things systematically to make an impact, so that had a huge influence, particularly on my principled actions and wardrobe". (Sle) 
"Externally, I looked to my father- my father was also a teacher, very dedicated. I learnt a lot from him in terms of discipline, punctuality and dedication to work. He shaped my life and actions." (Bec)

"The training my father gave me. He was proactive and he made me proactive so I grew up always thinking ahead ... So for me, that is the genesis of the planning". (Pon)

Relevant publics were mentioned by five (5) respondents. This included traditional leaders and past students. Per the respondents, these categories of relevant publics had vested interest in their respective colleges. They were well-represented on college councils so major decisions could not be taken without their inputs. Significant quotes are as follows:

"As an old student, I have a stake in the college. If you destroy it, you have destroyed your own school ... your own class mates will humiliate you. So, you must do things right". (Sle)

"One on one too ... some of the old students were consulted for advice”. (Soko)

The traditional people were watching. Closely, they watched (laughs). So we had to go by the "status quo". (Krop)

"I even called some of the past students to ask what they wanted done and how do they want their college to be like? They gave their ideas which became part of my agenda". (Buri)

The first thing I did was to make some changes in the administrative set up/hierarchy. Those changes were based on information I had from relevant people." (Roke)

\section{Discussion}

Literature notes that certain factors shaped the new principals' transition by influencing them in setting priorities and in determining what to do (Cockley, 2011; Meleis et al., 2000). In affirmation, this study found that during transitions, those involved made decisions and acted on them. Obviously, nothing takes place without a precipitating factor. Transition actions are not simply automatic. They are influenced by certain identified characteristics or properties. Internally, as discovered in this study, Ejimabo (2015), Cockley (2011), Gallos (2008), and Afful-Broni (2006) confirmed that one's own leadership style determine decisions, tools and the resources to execute the job and make or unmake a positive impact. As theorized, failure during the time of transition could have dire consequences (Gallos, 2008) a new principal should choose a leadership style relevant to the situation being inherited (Gallos, 2008; Fiedler, 1967, cited in Cole 2004). In terms of quality assurance, literature emphasizes decisions made based on available data (AffulBroni, 2006; Cockley, 2011), structures in place to improve academic performance and maintain discipline (Afful-Broni, 2006; Cockley, 2011), being circumspect in financial discipline (Afful-Broni 2006) and concentration on change and enhancement (Cockley, 2011).

Also, as recognized in this study, Cockley (2011) and Afful-Broni (2006) found that financial matters were central to the services rendered by administrators in any organization and every decision made by the school head had financial connotations. Afful-Broni (2006) further suggested that the head must be very circumspect in this sensitive area because any problem in this domain could break the leader and jeopardize the future of the institution. As noted in the study, provision of infrastructural and logistical needs, which is a strong determinant in goal attainment, is dependent on financial standing. It is, therefore, not surprising that I identified finance as a factor of the college principals' transition decisions. Hence, it is critical that in transition, principals secure and manage funds appropriately to meet set goals.

Again, in line with this study, existing school culture in terms of the "status quo" is a priority for immediate actions and decisions (Cockley, 2011; Ejimabo, 2015; Gallos, 2008; Schein, 2010). Obviously, culture has a significant role to play in transition decisions and actions but one must be mindful of the school culture in the context of national mandates. Also, motivation boosts morale to increase job performance but it was not 
a strong decision influencing factor in this study. However, Transforming Teacher Education and Learning (T-TEL, 2016) and Nguni et al. (2006) affirmed the need for motivation in job effectiveness and efficiency. Without motivation, interest and morale may reduce. This will invariably affect turnover, particularly in the case of a new principal who may aim at positive change and improvement. Gender responsiveness not being a strong factor in decision making could probably be attributed to cultural factors or limited knowledge on issues of gender as far as the college principals were concerned. Noteworthy is the ongoing T-TEL programs in Colleges of Education which emphasize the importance of gender in college management (T-TEL, 2016). This is in response to international calls for gender responsiveness and equality in education (UNESCO, 2015; UNESCO, 2011).

Internally, individuals who influenced transition decisions most were students. This is due to the assertion that in an era of testing and accountability, there is continued pressure to improve students' performance (Cockley, 2011). Hence, all decisions were centered on the students' achievement. Furthermore, in order to train teachers who will be effective and efficient, a new National Teacher Education Curriculum Framework (MoE, 2017) for Ghana was developed based on professional standards outlined in the National Teachers' Standards Guidelines for Ghana (National Teaching Council [NTC] 2017). This has resulted in a lot of decisions around students with regard to professional knowledge, professional values and attitudes, professional practice and the resources required to meet them. This affirms Cockley's (2011) findings that in a school with a designation of academic emergency or academic watch, the designation plays a huge part in their decisions such as focusing on meeting staffing and other basic needs, through social service agencies, testing data and character education to promote learning. Matthews and Crow (2003) also noted that within the school, the students influenced the socialization of the new principal and vice-principal. This, therefore, implies that students are key in new principals' tenure and automatically influence their actions and decisions.

The impact of individual principal's personal philosophy in transitions is affirmed by Cockley's (2011) findings that one's own personality and personal values and expectations influence decisions. Also, an understanding of personality dimension provides additional insight into how best to respond to them individually at each stage of the transition (Nguni et al., 2006). Though personal philosophies vary, undoubtedly, its influence on transition decisions is underscored. Essentially, the legacy of the previous principal's leadership style (Bagi, 2015; Shoho \& Barnett, 2010; Sieber, 2002) in terms of relationship established and leadership style (Cockley, 2011; Earley et al., 2013; Weindling \& Dimmock, 2006) must be "acknowledged" (Rooney, 2000, p. 77) as that helps to shape actions and decisions during the transition period. Assistant principals are also extremely professionals and supportive (Cockley, 2011; Matthews \& Crow, 2003). This affirms the influence of prior principals' legacy and leadership style on a new principal's decisions and actions as noted in this study.

This study did not emphasize the influence of college council, tutors and vice-principal on the new principals' decisions and actions. However, the roles of these groups of people in effective college management cannot be over emphasized as stressed in the Harmonized Statutes of the Colleges of Education (NCTE, 2015) and noted by Cockley (2011) and Matthews and Crow (2003). Hence, no decisions and actions can be taken on the college without staff involvement and the council's approval. The college council, tutors and vice-principals are key in college decisions.

Bridges and Mitchell (2000) noted that transition occurs in the course of every attempt at change. Undoubtedly, there must be innovation and that means change. The change is external and it involves the different policies, practices, or structures that the leader is trying to establish (Ejimabo, 2015; Bridges \& Mitchell, 2000). This affirms and explains why in this study, external factors such as transition of colleges to tertiary dominated. Also, expectations and needs of the community and background/experience were influential in decision making as regards policies, practices, or structures the new principals established for improvement. Furthermore, change is nothing new to leaders, or their constituents as organizations cannot achieve success if they do not re-align to contemporary practices (Bridges \& Mitchell, 2000). 
In line with the findings of the study, external individuals influence transition decisions. Role models are very relevant in the principals' transition. Their behaviour, attitudes and advice on how best to manage the transitions were worth emulating (Matthews \& Crow 2003). Also, literature notes that support and guidance provided by central office administration play a critical role in decision making (Cockley, 2011). Even though the findings of this study did not mention the influence of individuals within the central office administration or regulatory bodies in the Ghanaian context, it is worth noting that consultations with them will result in decisions that will most probably improve transition management. This probably explains why external individuals such as role models and relevant publics influenced decisions in this study and worth observing in transitions.

Literature reviewed (Cockley, 2011; Ejimabo, 2015; Matthews \& Crow, 2003) does not classify transition decision influencing factors as internal factors, internal individuals, external factors and external individuals as done in this study. However, the earlier findings still recognize and fall within the categories noted in this study. For instance, factors such as "district philosophy, district typology, school designation, superintendent and central office administration" identified (Cockley, 2011, pp. 156-171) are basically external considered in the stance of this study. Obviously, both internal and external factors and individuals influence the new principals' transition decisions. Once the college does not exist in isolation, its management will automatically be influenced by both factors. However, if the internal structures and systems are not adequately recognized and addressed appropriately to accept the external influence, the internal factors may not be very effective and could ruin the transition. Nonetheless, the actions and decisions were influenced more by internal and external factors and individuals rather than the principals' own personal beliefs. This affirms Cockley's (2011) findings that other factors rather than the principals' personal beliefs have more influence in the principal's transition decisions and actions. However, aggregatively, within the context of the categories of factors in this study, internal factors and individuals influenced the principal's transition actions and decisions more than external factors and individuals.

\section{Conclusions}

The findings showed that actions and decisions of the principals during their transitions were influenced by four categories of factors. The categories were basically "internal factors", "internal individuals", "external factors" and "external individuals". Nonetheless, the actions and decisions were influenced more by internal and external factors and individuals rather than the principal's own personal beliefs. Noteworthy is, aggregatively, within the context of the categories of factors in this study, internal factors and individuals were more influential than external factors and individuals in the principal's actions and decisions in the transition. Worth considering is that students play a key role in a new principal's decisions and actions. Hence, it is recommended that new principals should pay attention to internal and external factors and individuals, particularly students as they set transition goals, priorities and actions. This would help to align interests and reduce resistance to any change situation that may result from the transition.

\section{References}

[1] Afful-Broni, A. (2006). Theory and practice of educational leadership in Ghana. Accra-Ghana: Yamens Press Ltd.

[2] Bagi, S. (2015). Journeys into principalship: The experiences of beginning principals of independent schools. Griffith University. An unpublished $\mathrm{PhD}$ thesis.

[3] Ben-Eliyahu, A. (2013). Understanding different types of research: What's the difference between qualitative and quantitative approaches? New Jersey: Prentice Hall-Inc.

[4] Bridges, W. and Mitchell, S. (2000). Leading transition: A new model for change. Leader to Leader Journal, 16, 1- 19.

[5] Cockley, K. R. (2011). The transition experience: The first 100 days of the middle school principalship. An Unpublished Doctoral Dissertation. Kent State University.Retrieved from https://etd.ohiolink.edu/

[6] Creswell, J. W. (2014). Qualitative inquiry \& research design: choosing among five approaches (4th ed.). Thousand Oaks, CA: Sage 
[7] Creswell, J. (2009). Research design: Qualitative, quantitative, and mixed methods approaches $\left(3^{\text {rd }}\right.$ ed.). Thousand Oaks, CA: Sage.

[8] Creswell, J. W. (2007). Qualitative enquiry and research design: Choosing among five approaches. California: Sage Publications, Inc.

[9] Cunningham, H. L. (2000). It's the principal of the thing: A phenomenological study on the leadership role of the principal. Claremont Graduate University, Claremont, California. An unpublished doctoral dissertation.

[10] Dethloff, C. H. (2005). A principal in transition: An autoethnography. Doctoral dissertation, Texas A\&M University. Texas, United States of America. Retrieved on June 27, 2018 from https://core.ac.uk/download/pdf/4271803.pdf.

[11] Earley, P., Nelson, R., Higham, R., Bubb, S., Porritt, V., \& Coates, M. (2013). Experiences of new headteachers in cities. London: National College for School Leadership.

[12] Ejimabo, N. O. (2015). An approach to understanding leadership decision making in organization. European Scientific Journal, 11(11), 1-24.

[13] Fiedler, F. E. (1967). A theory of leadership effectiveness. In G. A. Cole (Ed.), Organizational behavior, theory and practice (p. 202). UK: Thompson learning.

[14] Gallos, J. (2008). Business leadership. San Fransisco, Ca: John Wiley \& Sons Inc.

[15] Hesselbein, F. (2012). The challenge of leadership transition. Retrieved from http://www.hesselbeininstitute.org/knowledgecenter/journal.aspx?ArticleID=148.

[16] Matthews, L. J. and Crow, G. M. (2003). Being and becoming a principal: Role conceptions for contemporary principals and assistant principals. Toronto: Pearson Education.

[17] Meleis, A. I., Sawyer, L. M., Im, E. O., Hilfinger Messias, D. K., \& Schumacher, K. (2000). Experiencing transitions: An emerging middle range theory. Advances in Nursing Science, 23(1), $12-28$.

[18] Miles, M. B., Huberman, A. M., \& Saldana, J. (2014). Qualitative data analysis: A methods sourcebook (3rd ed.). Thousand Oaks, CA: Sage.

[19] Ministry of Education (2017). The national teacher education curriculum framework: The essential elements of initial teacher education. Accra: Ministry of Education.

[20] National Council for Tertiary Education (2015). Harmonized statutes for colleges of education. Accra: National Council for Tertiary Education.

[21] National Teaching Council (2017). National teachers' standards for Ghana: Guidelines. Accra: National Teaching Council.

[22] Transforming Teacher Education and Learning [T-TEL] (2016). Unit 3: Leading institutional strengthening (operations leadership) - leadership program resources for college leaders. Ghana: Ministry of Education.

[23] Nguni, S., Sleegers, P. and Denessen, E. (2006). Transformational and transactional leadership effects on teachers' job satisfaction, organizational commitment, and organizational citizenship behavior in primary schools: The Tanzanian case. School Effectiveness and School Improvement, 17(2), 145-177.

[24] Patton, M. Q. (2015). Qualitative Research and evaluation methods (4 ${ }^{\text {th }}$ ed.). Thousand Oaks: Sage Publications.

[25] Rooney, J. (2000). Survival Skills for the New Principal. Educational Leadership and Administration, 58(1), 77-78.

[26] Schein, E. H. (2010). Organizational culture and leadership (4 ${ }^{\text {th }}$ ed.). San Francisco: Jossey-Bass.

[27] Sieber, A. (2002). No regrets? Starting secondary headship. Nottingham: NCSL.

[28] Shoho, A. R. and Barnett, B. G. (2010). The realities of new principals: Challenges, Joys, and sorrows. Journal of School Leadership, 20(5), 561-596.

[29] UNESCO (2015). A guide for gender equality in teacher education policy and practice. Paris: UNESCO.

[30] UNESCO (2011). Teacher training modules that address gender issues and promote gender equality. Ministry of Education and Training (MoET) in Vietnam, Vietnam Institute of education 
sciences (VNIES), Department of Teachers and educational Administrators of MoET in Vietnam. Hanoi: UNESCO.

[31] Weindling, D. and Dimmock, C. (2006). Sitting in the "hot seat": New headteachers in the UK. Journal of Educational Administration, 44(4), 326-340.

[32] Yeatts, M. L. (2005). Before turning over the keys to the new principal. School Administrator, 62(6), 16-19. 